\title{
Development, validation and cultural-adaptation of the knowledge about psychosis questionnaire for African- Caribbean people in the UK
}

DOI:

10.1016/j.psychres.2018.03.013

\section{Document Version}

Accepted author manuscript

Link to publication record in Manchester Research Explorer

Citation for published version (APA):

Degnan, A., Berry, K., James, S., \& Edge, D. (2018). Development, validation and cultural-adaptation of the knowledge about psychosis questionnaire for African-Caribbean people in the UK. Psychiatry Research, 263, 199206. https://doi.org/10.1016/j.psychres.2018.03.013

Published in:

Psychiatry Research

\section{Citing this paper}

Please note that where the full-text provided on Manchester Research Explorer is the Author Accepted Manuscript or Proof version this may differ from the final Published version. If citing, it is advised that you check and use the publisher's definitive version.

\section{General rights}

Copyright and moral rights for the publications made accessible in the Research Explorer are retained by the authors and/or other copyright owners and it is a condition of accessing publications that users recognise and abide by the legal requirements associated with these rights.

\section{Takedown policy}

If you believe that this document breaches copyright please refer to the University of Manchester's Takedown Procedures [http://man.ac.uk/04Y6Bo] or contact uml.scholarlycommunications@manchester.ac.uk providing relevant details, so we can investigate your claim.

\section{OPEN ACCESS}




\section{Manuscript Details}

\section{Manuscript number}

Title
PSY_2017_1166_R2

Development, validation and cultural-adaptation of the knowledge about psychosis questionnaire for African-Caribbean people in the UK

Full Length Article

\section{Article type}

Abstract

The absence of assessment tools incorporating different cultural models of mental illness is a major barrier to recruiting ethnic minorities into clinical trials, reducing generalisability of findings and potentially increasing disparities in access to evidence-based care. This study aimed to develop and validate a new Knowledge about Psychosis (KAP) self-report measure and a culturally-adapted version for African-Caribbean people (CaKAP). Content and face validity were achieved through consultations with experts in psychosis and a focus group with service users, carers, and community members. Eighty-seven predominantly White British participants and 79 African-Caribbean participants completed the knowledge questionnaires (KAP and CaKAP) and measures of help-seeking and stigma. Overall, the measures showed good internal consistency and test re-test reliability. Construct validity was evidenced via significant positive associations between knowledge about psychosis and help-seeking and significant negative associations between knowledge and stigma. These measures could improve delivery of psychosocial interventions and outcome measurement in research trials.

\section{Keywords}

\section{Corresponding Author \\ Corresponding Author's Institution}

Order of Authors

Suggested reviewers
Psychosis; Schizophrenia; Psychometric validation; Cultural-adaptation; Ethnic minorities; Stigma; Help-seeking; Knowledge; African-Caribbean; Black-

Caribbean; Family Intervention

Amy Degnan

The University of Manchester

Amy Degnan, Katherine Berry, Susanna Jenkins, Dawn Edge

Ilyas Mirza, Shanaya Rathod, Andrew Beck, Farooq Naeem, Stephanie Minchin

\section{Submission Files Included in this PDF}

\section{File Name [File Type]}

Cover letter to editor 05.03.18.docx [Cover Letter]

Letter to reviewers 05.03.18.docx [Response to Reviewers]

KAP highlights_PR_16.07.17.docx [Highlights]

KAP abstract_PR_final submission 5.3.18.docx [Abstract]

FINAL MANUSCRIPT_5.3.18.doc [Manuscript File]

KaP questionnaire.docx [Supporting File]

CaKAP questionnaire.docx [Supporting File]

To view all the submission files, including those not included in the PDF, click on the manuscript title on your EVISE Homepage, then click 'Download zip file'.

\section{Research Data Related to this Submission}

There are no linked research data sets for this submission. The following reason is given:

Data will be made available on request 
Division of Psychology and Mental Health Faculty of Biology, Medicine and Health Second Floor Zochonis Building The University of Manchester Oxford Road, Manchester, M13 9PL

Email: amy.degnan@manchester.ac.uk

$5^{\text {th }}$ March 2018

Dear Professor Buchsbaum,

RE: Manuscript: Development, validation and cultural-adaptation of the knowledge about psychosis questionnaire for African-Caribbean people in the UK

Thank you for the accepting the above manuscript. I have now removed tracked changes and uploaded a finalised version of the manuscript and abstract

Yours sincerely,

Amy Degnan

On behalf of all authors 
Division of Psychology and Mental Health

Faculty of Biology, Medicine and Health

Second Floor Zochonis Building

The University of Manchester

Oxford Road, Manchester, M13 9PL

Email: amy.degnan@manchester.ac.uk

$5^{\text {th }}$ March 2018

Dear Reviewers,

RE: Manuscript: Development, validation and cultural-adaptation of the knowledge about psychosis questionnaire for African-Caribbean people in the UK

Thank you for your comments on the above manuscript. I have now removed tracked changes and uploaded a finalised version of the manuscript and abstract.

Yours sincerely,

Amy Degnan

On behalf of all authors 


\section{Highlights}

- Increasing knowledge about psychosis is a key target for psychosocial interventions

- Existing knowledge measures are outdated and based on Western models of illness

- We present a reliable and valid measure of knowledge about psychosis (KAP)

- We culturally-adapt KAP for African-Caribbean service users and carers (caKAP)

- These tools can be used to assess outcomes in research trials and clinical practice 


\section{Abstract [151 words]}

The absence of assessment tools incorporating different cultural models of mental illness is a major barrier to recruiting ethnic minorities into clinical trials, reducing generalisability of findings and potentially increasing disparities in access to evidence-based care. This study aimed to develop and validate a new Knowledge about Psychosis (KAP) self-report measure and a culturally-adapted version for African-Caribbean people (CaKAP). Content and face validity were achieved through consultations with experts in psychosis and a focus group with service users, carers, and community members. Eighty-seven predominantly White British participants and 79 African-Caribbean participants completed the knowledge questionnaires (KAP and CaKAP) and measures of helpseeking and stigma. Overall, the measures showed good internal consistency and test re-test reliability. Construct validity was evidenced via significant positive associations between knowledge about psychosis and help-seeking and significant negative associations between knowledge and stigma. These measures could improve delivery of psychosocial interventions and outcome measurement in research trials. 
Development, validation and cultural-adaptation of the knowledge about psychosis questionnaire for African-Caribbean people in the UK

\section{Authors}

Amy Degnan*, Katherine Berry ${ }^{* *}$, Susannah James, Dawn Edge ${ }^{* *}$

Division of Psychology and Mental Health, Faculty of Biology, Medicine and Health, The University of Manchester, Manchester, England

\section{* Corresponding author}

amy.degnan@manchester.ac.uk

01612755224

Division of Psychology and Mental Health, Faculty of Biology, Medicine and Health, The University of Manchester, Room 3.306, Jean McFarlane Building; Oxford Road, Manchester, M13 9PL

**Co-Corresponding authors

dawn.edge@manchester.ac.uk

katherine.berry@manchester.ac.uk

\section{Abbreviations:}

CAFI $=$ Culturally-adapted Family Intervention

$\mathrm{KAP}=$ Knowledge about Psychosis

CaKAP $=$ Culturally-adapted Knowledge about Psychosis 


\section{Introduction}

Psychosis is a severe mental health problem associated with high levels of distress, loss of function, and substantial economic and social burden (The Schizophrenia Commission, 2012). It is well established that migrant and ethnic minority groups have the highest diagnostic rates of schizophrenia and other psychoses (Cantor-Graae and Selten, 2005; Kirkbride et al., 2006). In the United Kingdom (UK), people of African-Caribbean backgrounds ${ }^{1}$ are at greatest risk of being diagnosed with psychoses, with schizophrenia rates two to 14 times higher than White British people (Fearon et al., 2006). They also experience the greatest inequalities of mental healthcare when compared to all other ethnic groups in the UK (Bhui et al., 2003).

Perceived institutional discrimination and adverse experiences are suggested contributors to mistrust of mental health services and reduced help-seeking in the African-Caribbean community (Singh et al., 2007). Delayed access to care increases the duration of untreated symptoms and illness acuity on contact with services, increasing African-Caribbean peoples' risk of accessing care via adversarial routes such as compulsory detention under the Mental Health Act (HM Government, 2007) and police involvement (Morgan et al., 2005). Whilst in services, African-Caribbean people receive more coercive treatment and are less likely to be offered psychological therapy (Morgan et al., 2004). It has been argued that adverse care pathways and negative service experiences create a vicious 'circle of fear' (Keating et al., 2002) that reinforces avoidance of and disengagement from mental health services leading to poorer outcomes such as longer hospital stays and higher rates of relapse and hospital readmission.

In response to such ethnically-based disparities, there has been increased interest in adapting evidence-based interventions to meet the needs of minority ethnic populations (Edge et al., 2016; National Institute for Health and Care Excellence, 2009; Rathod et al., 2013). However, to our knowledge, there has been little work to develop culturally-appropriate tools to assess outcomes for these groups in clinical and research settings. African-Caribbean people have previously reported culturally-specific models of mental illness; including beliefs in spiritual causes, such as $\mathrm{Obeah}^{2}$, and the use of more traditional methods of healing (Rathod et al., 2010). Findings like these emphasise that the use of assessment tools that are only informed by Western mental health models might not be suitable for diverse ethnic groups. Inappropriateness of assessment tools has recently been identified as a major barrier to recruiting ethnic minorities to mental health research and one reason for their underrepresentation in clinical trials (Brown et al., 2014; Waheed et al., 2015). The inclusion of ethnic

\footnotetext{
${ }^{1}$ This term is being used to describe people of African-Caribbean heritage who may not have been in the Caribbean themselves, including people who define their ethnicity as 'Black British' and 'Mixed Heritage'.

${ }^{2}$ Obeah is a term used in the Caribbean to describe religious practices, magic and folk medicine derived from religions of West African slaves [28]
} 
minorities in clinical trials is important for increasing the generalisability of findings (Waheed et al., 2015).

We recently tested the feasibility of developing and implementing Culturally-adapted Family Intervention (CAFI) for African-Caribbean people in the UK (Edge et al., 2016). Family Intervention (FI) is an evidence-based intervention for psychosis and schizophrenia (Pharoah et al., 2010) recommended by UK and USA national guidelines (Dixon et al., 2010; National Institute for Health and Care Excellence, 2014). Delivering culturally-sensitive FI is particularly relevant for AfricanCaribbean people as there is an increased risk of family breakdown and greater burden of care on families (Awad and Voruganti, 2008; Mallett et al., 2002; Morgan et al., 2007). Psychoeducation to improve knowledge about psychosis, including its aetiology, presentation and management, is a core component of FI and other psychosocial interventions (McFarlane et al., 2003). African-Caribbean people are likely to benefit from psychoeducation as service users report a lack of knowledge about mental health problems in these communities (Shefer et al., 2013) and an over-reliance on information existing within their social networks (Kovandžić et al., 2011). Limited knowledge about psychosis also contributes to disproportionate involvement of the police in African-Caribbean people's care pathways. Service users' relatives often contact the police versus mental health professionals in crisis situations following multiple attempts to seek-help (Morgan et al., 2004; Shefer et al., 2013). Despite these barriers, our feasibility study showed that FIs that are specifically tailored to the needs of African-Caribbean people can facilitate engagement and retention in treatment. To evaluate the outcomes and benefits of these interventions, we need to develop culturally-appropriate assessment tools.

As psychoeducation is a core component of psychological interventions for psychosis, validated assessment tools are needed that measure its effects across different groups in research and clinical settings. The Knowledge about Schizophrenia Interview (KASI) (Barrowclough et al., 1987; Barrowclough \& Tarrier, $1992^{3}$ ) was developed over three decades ago as a clinical tool to inform the delivery of psychoeducation as part of Barrowclough and Tarrier's FI (1992). However, KASI's content and language are outdated and the tool has not been revised since its initial development. Moreover, the psychometric properties of the KASI are unknown, and the interview can take more than 30 minutes to complete. An updated and less burdensome measure of knowledge is needed and should be validated to assess therapeutic outcomes for psychosis in research trials and clinical practice. Furthermore, like traditional FI, the KASI was developed in a Western context and it is unclear to what extent the tool is appropriate for African-Caribbeans or indeed other ethnic groups. Given the over-representation of African-Caribbean people among those diagnosed with psychosis,

\footnotetext{
${ }^{3}$ The KASI is provided in the appendices of Barrowclough \& Tarrier's (1992) book.
} 
developing a measure of knowledge that incorporates the culturally-specific illness models of this population is warranted.

Empirical research in non-clinical samples suggests that improved knowledge about mental illness leads to increased intentions to seek professional help (Rüsch et al., 2011) and less stigmatising attitudes relating to mental illness (Mas and Hatim, 2002). Public stigma (negative views of mental health problems by others) predicts self-stigma (the internalisation of public stigma), and both have been shown to influence individuals' willingness to seek psychological help for mental health problems (Vogel et al., 2007). High expectations of being stigmatised is common for people experiencing psychosis (Wood et al., 2014), particularly those of African-Caribbean backgrounds (Rathod et al., 2010). Perceptions of stigma may lead to avoidant behaviours, prevent disclosure and help-seeking for psychosis (Kovandžić et al., 2011; Pyle and Morrison, 2013). Qualitative research suggests that beliefs about the causes of mental illness and 'silencing' of mental illness due to stigma influences help-seeking responses in African-descended communities (Mantovani et al., 2017; Shefer et al., 2013). Psychoeducation to improve knowledge about psychosis, such as its presentation and available mental health treatments, could increase intentions to seek help and therefore reduce the delayed access to services that is particularly pertinent among African-Caribbean groups in the UK.

This study had two main aims: 1) to develop an updated and validated version of the KASI, the Knowledge about Psychosis (KAP) questionnaire; and 2) to culturally-adapt this measure for AfricanCaribbean people to create the Culturally-adapted Knowledge about Psychosis (CaKAP) questionnaire. Reliability of the KAP and CaKAP measures were examined using internal consistency scores on two individual samples and test-retest reliability analyses on a sub-sample of participants two weeks later. In terms of construct validity, it was hypothesised that greater knowledge on both the KAP and CaKAP would correlate with more positive attitudes towards help-seeking and lower levels of perceived stigma, and that help-seeking and stigma would negatively correlate with each other.

\section{Methods}

\subsection{Development of the Knowledge about Psychosis (KAP) Questionnaire}

\subsubsection{Updating the KASI}

We developed the KAP questionnaire drawing on expertise from the research team, a review of the literature and current empirical evidence. The six subscales and structure of the KAP were derived and modified from the KASI (Barrowclough et al., 1987; Barrowclough and Tarrier, 1992). For ease of reporting, the KAP subscales will be referred to as: SYMPTOM (symptoms and problems relating 
to psychosis); CAUSE (cause); MED (medication); TREAT (other treatments and services); OUTCOME (course and outcome); and MANAGE (management).

Through literature searching and discussions with colleagues in the field, we came across a related measure, the Knowledge about Psychosis Interview (KAPI) (Smith et al., 2007). The KAPI replaces language and terminology to be consistent with a model of 'psychosis' rather than 'schizophrenia' but mirrors the KASI in terms of its content, structure and scoring. In line with KAPI, it was agreed that the term 'psychosis' would be used as it has a broader application (e.g. interventions for first episode psychosis) and is more in line with current practice. In contrast to the more burdensome interview format of the KASI and KAPI, we selected a self-report questionnaire format for the KAP to improve its efficiency and allow ease of completion in research and clinical settings. We envisaged clinicians would use the questionnaire to structure a more detailed discussion about relatives' current understanding about service users' experiences.

Scoring of the KAP questionnaire was simplified by using 2 points for Agree, 1 point for Don't Know and 0 points for Disagree. The 'correct response' for the items was based on team expertise and current evidence and guidelines in the UK (National Institute for Health and Care Excellence, 2014; The British Psychological Society, 2014).

\subsubsection{Item generation}

Expert advice and consensus between research team members was sought by regular meetings to agree on the KAP items, including those derived from the KASI and additional items. Updating the content of the KAP included changing items, for example updating current treatments (TREAT) to be consistent with those recommended in the most recent guidance (Dixon et al., 2010; National Institute for Health and Care Excellence, 2014), and adding items, for example adding 'paranoia' to the list of symptoms (SYMPTOM). Careful attention was paid to the wording of the KAP to ensure it was less stigmatising and more accessible, for example by using the term 'unusual beliefs' versus 'false beliefs' (SYMPTOM). To normalise the experience of psychosis, in the hope of reducing perceptions of stigma, items such as 'Psychotic experiences are experienced by up to $10 \%$ of the general population at some point in their lives' were also included (SYMPTOM).

\subsubsection{Content validity}

Content validity (CV) assessments (Haynes et al., 1995) examined the extent to which the initial KAP items were relevant to the target construct, that is, the measurement of factual knowledge about the symptomology, cause, medication, treatment, prognosis and management of psychosis in the UK general population based on current evidence. Eleven expert clinical academic rated each item on a four-point Likert scale ranging from 1 (irrelevant) to 4 (extremely relevant) (Lynn, 1986). The Content Validity Index (CVI) was calculated by dividing the number of items rated as three or four by 
the number of experts (Lynn, 1986). Seven items scored below the 0.80 threshold and were therefore removed from the KAP; these included four false positive (reverse-scored) items (e.g. MANAGE: 'Giving them a good push to get going with things'; and SYMPTOM: 'People experiencing psychosis are always responsible for their symptoms').

\subsection{Development of the Culturally-adapted Knowledge about Psychosis Questionnaire (CaKAP)}

\subsubsection{Cultural adaptation of the KAP}

The CaKAP included the same items as the KAP with additional culturally-specific items. The structure, format and scoring of the KAP questionnaire subscales were retained for consistency and to allow comparison between the two measures for items that overlap [see 2.3.3 for description of measures].

\subsubsection{Culturally-specific item generation}

Secondary analysis of focus group transcripts and review of the literature relating to AfricanCaribbean experiences of psychosis were used to generate culturally-specific items. The transcripts were derived from three focus groups with African-Caribbean people (service users; carers and advocates; community members) conducted as part of the senior author's [DE] feasibility study (Edge et al., 2016). Qualitative data from these transcripts and published papers (e.g. Kovandžić et al., 2011; Rathod et al., 2010; Shefer et al., 2013) were analysed and culturally-specific items for the CaKAP subscales were generated deductively, until saturation was reached.

Cultural-adaptations included the addition of risk factors specific to African-Caribbean people derived from qualitative data including institutional racism, unfulfilled expectations, racist attacks/events, discrimination and social exclusion (CAUSE); who to contact in crisis, as African-Caribbean people are more likely to enter services at this stage (TREAT); additional factors might worsen illness experiences such as stigma, mistrust of services, and self-medicating with illicit drugs (OUTCOME); and emphasis on cultural means of coping such as prayer and support from faith-based organisations and personnel (TREAT and MANAGE).

\subsubsection{Face validity}

Face validity (FV) was examined to measure the extent to which the CaKAP was acceptable to African-Caribbean people in terms of language and layout, user-friendliness and culturallyappropriateness (DeVon et al., 2007). The measure was presented to a Research Advisory Group (RAG) of eight African-Caribbean service users, carers and community members established for the CaFI study (Edge et al., 2016). Two researchers [AD and SJ] conducted a two-hour focus group with the RAG using a semi-structured interview designed for this study. RAG members agreed that the 
content of the CaKAP was culturally-acceptable and the additional items improved its relevance to African-Caribbeans.

Qualitative feedback informed further changes to the layout, format and wording to increase accessibility. For example, 'using illicit drugs' (SYMPTOM, CAUSE and OUTCOME) and 'social deviance' (CAUSE) were not universally understood so were changed to 'misusing drugs' and 'antisocial behaviour', respectively. One item (i.e. SYMPTOM: 'Some people find psychotic experiences positive') originally deleted from the KAP based on CV expert feedback [see 2.1.3] was re-added to the KAP and CaKAP based on FV feedback and having a CV index of 0.73 , close to the threshold of 0.80 . For consistency, and to improve the readability and comparison of the two measures, changes to the layout, format and wording of items were made to both the KAP and CaKAP.

\subsection{Construct validity and reliability assessments of the KAP and CaKAP}

\subsubsection{Design}

To assess construct validity, a cross-sectional design was used to correlate the KAP and CaKAP with established measures of help-seeking attitudes and stigma. Test-retest reliability was assessed using a longitudinal repeated measures design to compare participant responses between Time 1 and Time 2, with a two-week interval.

\subsubsection{Participants}

Eighty-seven predominately White British students and staff members from a university in the North West of England took part in the KAP online survey via advertisement materials (e.g., announcements on weekly student/staff emails, University website/intranet, and posters at University sites).

For the CaKAP, 79 African-Caribbean participants were recruited from Black-majority churches and community groups via emails, presentations and posters. CaKAP participants identified their ethnic origin as African-Caribbean with at least one grandparent born in the Caribbean of African descent (including people of 'Mixed' heritage).

Participants in both samples were entered in to a prize draw as compensation for their time.

\subsubsection{Measures}

The Knowledge about Psychosis (KAP) questionnaire

The KAP is a self-report questionnaire assessing knowledge about psychosis. It includes six subscales: i) Symptoms and problems relating to psychosis (SYMPTOM, 26 items); ii) Cause (CAUSE, 4 items); iii) Medication (MED, 16 items); iv) Other treatments and services (TREAT, 9 items); v) Course and outcome (OUTCOME, 10 items); and vi) Management (MANAGE, 3 items). Subscales 
include questions, for example 'Which of the following are symptoms associated with psychosis?' followed by lists of items, for example 'Hearing things that others are not hearing'. Items are scored 2 points for 'Agree', 1 point for 'Don't Know' and 0 points for 'Disagree'. Item scores can be summed to generate subscale and total scores (range $=0-136$ ). Total scores equate to improved knowledge of psychosis. The KAP also includes open-ended questions to expand on items within each subscale (e.g. 'Are there any other treatments you can think of?'). The KAP can be found in online supplementary materials.

\section{The Culturally-adapted Knowledge about Psychosis (CaKAP) questionnaire}

The CaKAP comprises the same subscales and items as the KAP, with additional culturally-specific items for African-Caribbean respondents. CaKAP includes 23 culturally-specific items in four of six subscales: CAUSE includes seven (11 items), TREAT includes six (15 items), OUTCOME includes six (16 items), and MANAGE includes two (5 items). An example item for CAUSE is 'Spiritual causes such as Obeah/demons'. The SYMPTOM and MED subscales include no culturally-specific items. The structure and response format is the same as the KAP. The culturally-specific CaKAP items are not scored as correct or incorrect; instead, higher scores equate to higher endorsement of culturallyspecific beliefs about psychosis (range $=0-46$ ). These items highlight different cultural beliefs about the cause, treatment, outcome and management of psychosis that can be used to guide clinical practice and intervention. The KAP items can be summed and scored to assess knowledge about psychosis (range $=0-136$ ). For the purpose of this study, to analyse construct validity, the total score (culturallyspecific plus KAP items) was used. The CaKAP is available in online supplementary materials.

Inventory of Attitudes Towards Seeking Mental Health Services (IATSMHS) (Mackenzie et al., 2004)

The IATSMHS is a 24-item self-report inventory measuring attitudes towards seeking help from mental health services. The subscales include Psychological openness, the extent to which one is open to acknowledging problems; Help-seeking propensity, the extent to which one is willing and able to seek help; and Indifference to stigma, the extent to which one is concerned about others' views about help-seeking. Responses are rated on a 5-point Likert scale from 0 (disagree) to 4 (agree). Higher total scores reflect more positive help-seeking attitudes. The IATSMHS has high validity and reliability (alpha coefficient $=0.87$ ) (Mackenzie et al., 2004).

\section{The Devaluation-Discrimination Scale (DDS) (Link et al., 1991)}

The DDS is a 12-item self-report scale measuring perceptions of public mental health stigma (defined as the extent to which someone will be devalued or discriminated against because of their mental health problems) and therefore can be applied to a non-clinical sample. Awareness of public stigma is known to contribute to the internalisation of stigma, or 'self-stigma' (Bathje and Pryor, 2011; Vogel et al., 2007). Respondents rate each item on a 6-point Likert scale from 1 (strongly agree) to 6 (strongly 
disagree). Total scores are calculated by summing item scores; higher scores indicating greater levels of perceived stigma. The scale has high validity and reliability (alpha coefficient $=0.82$ ) (Link et al., 1991).

\subsubsection{Procedure}

Advertisement materials directed participants to an online survey with the participant information sheet and consent form. Consenting participants completed a demographic questionnaire which directed them to the KAP or CaKAP, followed by the IATSMHS and the DDS. All participants were emailed two weeks later, inviting them to complete the KAP or CaKAP within one week. The study was approved by the University Research Ethics Committee (ethics/15162).

\subsubsection{Data analysis}

Data were analysed using SPSS Version 22. Internal consistency was examined using Cronbach's Alpha Coefficient and test-retest reliability was assessed using Intraclass Correlation Coefficients (ICCs). Construct validity for the KAP and CaKAP was examined by conducting bivariate correlations with IATSMHS and DDS. Histograms and kurtosis and skewness z-scores were reviewed to determine normality. MANAGE in the KAP (for both samples) and MANAGE the CaKAP were skewed (Field, 2013). Transformations were performed but did not improve the distribution. Spearman correlation coefficients were calculated for non-normally distributed data but as the values were similar to the Pearson's coefficients, the parametric results are reported. Differences between the KAP and CaKAP samples on socio-demographics were examined using independent $t$-tests and chisquared tests (with Fisher's exact test when group $\mathrm{n}<.5$ ). Differences between KAP and CaKAP samples on measures (KAP, IASMHS and DDS) were examined using ANCOVAs to control for potential confounds. Cases with missing data were excluded from the analysis (i.e. listwise deletion).

\section{Results}

\subsection{Sample characteristics}

Table 1 shows sociodemographic characteristics of the KAP and CaKAP participants. Independent $t$ tests indicated that the Caribbean (CaKAP) sample were significantly older than the predominately White (KAP) sample $(t(130)=-7.55, p=.000)$. Chi-squared tests showed that CaKAP participants were more likely to have personal experience of psychosis $\left(X^{2}(1)=34.09, p=.000\right)$ and less likely to have studied psychology $\left(X^{2}(1)=19.80, p<.001\right)$. Chi-square tests (with Fisher's exact test) showed a significant association between sample and type of profession $\left(X^{2}(2)=63.53, p=.000\right)$. Gender and professional experience of psychosis did not differ between samples. 
Mean scores, standard deviations and ranges of the measures for the KAP and CaKAP samples are shown in Table 2. Controlling for age, there were no significant differences in total KAP ( $\mathrm{F}(1$, $118)=0.18, p=0.68)$, IASMHS $(\mathrm{F}(1,120)=0.18, p=0.68)$ and $\operatorname{DDS}(\mathrm{F}(1,123)=1.205, p=.274)$ when comparing the KAP and the CaKAP sample.

\subsection{Internal consistency}

Cronbach's alpha coefficients indicated good internal reliability for the total KAP $(\alpha=0.87)$, SYMPTOMS $(\alpha=0.79)$, and MED $(\alpha=0.75)$; but poor for CAUSE $(\alpha=0.51)$, TREAT $(\alpha=0.62)$, OUTCOME $(\alpha=.52)$ and MANAGE $(\alpha=0.41)$. Reliability was improved when removing item 2.1a (Having close relatives with psychosis) from CAUSE ( $\alpha=.61)$; item 4.1c (Arts therapies (e.g. art, drama, dance, music)) from TREAT $(\alpha=0.64)$; item $5.2 \mathrm{~d}$ (Have long term experiences of psychosis but do not require support) from OUTCOME $(\alpha=0.54)$; and item 6.1a (Supporting them in taking medication $)$ from MANAGE $(\alpha=0.64)$.

Good internal reliability was demonstrated for the total CaKAP $(\alpha=0.88)$, SYMPTOM $(\alpha=0.80)$, MED $(\alpha=0.79)$, OUTCOME $(\alpha=0.72)$, TREAT $(\alpha=0.72)$ and CAUSE $(\alpha=0.74)$. CaKAP MANAGE had poor internal consistency $(\alpha=0.40)$ - this slightly improved $(\alpha=0.48)$ when removing item 6.1a (Supporting them in taking medication).

\subsection{Test-retest reliability}

To evaluate test-retest reliability, 29 (33.3\%) participants completed the KAP and 12 (15.2\%) participants completed the CaKAP two weeks after the initial survey. Due to low numbers, the two samples were combined to examine test-reliability of the KAP in a total of 41 participants.

Test-retest correlation coefficients were excellent for total KAP scores $(I C C=0.82$, confidence interval $(\mathrm{CI})=0.65$ to $0.90 p<.001)$, SYMPTOM $(I C C=0.87, \mathrm{CI}=0.75$ to $0.93, p<.001)$ and OUTCOME (ICC $=0.80, \mathrm{CI}=0.62$ to $0.90, p<.001)$, acceptable for TREAT (ICC $=0.55, \mathrm{CI}=.16$ to $0.76, p<.001)$ and CAUSE (ICC $=0.63, \mathrm{CI}=0.31$ to $0.81, p<.001$ ); and poor for MANAGE (ICC=0.41, $\mathrm{CI}=-.12$ to 0.69 , $p<.001)$ and $\operatorname{MED}($ ICC $=0.33, \mathrm{CI}=-2.62$ to $0.65, p<.001)$.

\subsection{Construct validity}

Pearson's correlation coefficients between total and subscale scores on the KAP, CaKAP and IASMHS and total DDS scores are presented in Tables 3 and 4 (KAP and CaKAP sample, respectively).

Consistent with our hypotheses, significant negative correlations were found between total scores on the IASMHS and the DDS in both samples. 
As predicted, in the KAP sample, KAP total scores were significantly and positively associated with overall help-seeking (IASMHS total) and negatively with public stigma (DDS total). KAP TREAT and OUTCOME significantly positively correlated with overall help-seeking (IASMHS total), and KAP TREAT and MANAGE significantly negatively correlated with public stigma (DDS total). When examining significant correlations between IASMHS subscales and KAP scores, IASMHS Help-seeking propensity positively correlated with KAP total, SYMPTOM, TREAT and OUTCOME, and IASMHS Psychological openness correlated positively with KAP TREAT and OUTCOME.

Contrary to predictions, in the CaKAP sample, CaKAP total score did not correlate with total scores on IASMHS or DDS. For the subscales, CaKAP TREAT was significantly positively correlated with IASMHS Psychological Openness, Help-seeking propensity and overall help-seeking (IASMHS total), and CaKAP MED was negative associated with IASMHS Indifference to stigma.

\section{Discussion}

This study updated the Knowledge about Schizophrenia Interview (KASI) (Barrowclough and Tarrier, 1992), a well-established but outdated and psychometrically questionable measure. This study is also the first to develop a culturally appropriate measure of knowledge about psychosis for AfricanCaribbean people (CaKAP) and assess its psychometric properties. Face and content validity of the measures were determined by consultations with service users, carers, community members and healthcare professionals. Reliability and construct validity for the KAP and CaKAP were assessed in respective predominately White and African-Caribbean samples.

There were no significant differences between the predominately White versus the African-Caribbean sample in the knowledge about psychosis (KAP), stigma or help-seeking measures. This is surprising given previous research emphasising reduced knowledge about mental illness (Kovandžić et al., 2011), and high levels of stigma and negative help-seeking attitudes (Kovandžić et al., 2011; Mantovani et al., 2017; Rathod et al., 2010; Shefer et al., 2013) among African-Caribbean people. This may be because previous research is mostly qualitative and/or uses combined ethnic minority groups. Our literature review yielded one study reporting the specific experiences of AfricanCaribbean people with psychosis (Rathod et al., 2010). These findings suggest African-Caribbean and other ethnic groups may share common perceptions relating to psychosis. However, it is unclear whether they would uphold among service users with experience of psychosis and their relatives. Further research is needed to explore ethnic differences in the relationships between knowledge, stigma and help-seeking across both non-clinical and clinical populations.

Both the KAP and CaKAP had good levels of internal consistency overall suggesting that levels of knowledge about psychosis are relatively consistent across different domains of knowledge. Overall, the measures' subscales also demonstrated good internal consistency, suggesting that people have 
similar levels of knowledge in relation to each domain of knowledge. There were, however, a few exceptions, with lower alphas reported for the CAUSE, TREAT and OUTCOME subscales on the KAP and the MANAGE subscale on both the KAP and CaKAP. The alpha for KAP CAUSE improved when the item 'Having close relatives with psychosis' was removed and, whilst people on the whole endorsed causal items listed on the measure, this item was one of the least endorsed. This finding supports studies suggesting that the general population tend to favour psychosocial over biological causes of mental health problems (Geekie and Read, 2009). The alpha for KAP TREAT improved when the item relating to the benefits of art therapies was removed. We noted that this was often an item that people did not tend to endorse despite endorsing other treatments, which might reflect the relatively smaller evidence base for these therapies and their availability within mental health services (National Institute for Health and Care Excellence, 2014; The Schizophrenia Commission, 2012). The alpha for KAP OUTCOME improved when the item 'Have long term experiences of psychosis but do not require support' was removed which may reflect the common portrayal of psychosis as a chronic condition requiring lifelong treatment (Geekie and Read, 2009). The alpha for MANAGE was improved on the KAP and CaKAP when the item 'Supporting them in taking medication' was removed, suggesting people tended not to endorse this item as much as other items and possibly reflecting conflicting beliefs about medication in the current samples.

The KAP demonstrated good test-retest reliability over a two-week period which suggests that, in the absence of intervention, individuals' knowledge about psychosis are relatively stable at least over short time periods. This finding is consistent with previous research investigating the stability of illness perceptions and beliefs about psychosis (e.g. Lobban et al., 2005). Insufficient people from the African-Caribbean sample completed the CaKAP within the two-week window to enable adequate assessment of test re-test reliability within this specific subgroup, although we have no reason to hypothesise that knowledge would be any less stable in this group over a short period of time.

In support of construct validity and in line with previous research (Mas and Hatim, 2002; Rüsch et al., 2011), increased knowledge on the KAP was related to more positive help-seeking attitudes and lower levels of stigma. These findings suggest that improved knowledge about psychosis may facilitate greater intention to seek help and attenuate the belief that people will be discriminated against because of their symptoms. Overall, there were relatively less consistent associations between the CaKAP and the measure of stigma and help-seeking compared to the KAP. The concepts of stigma and helpseeking are likely to be influenced by a multitude of factors in an African-Caribbean population which were not measured as part of this study, including personal experiences of racism, past experiences of help-seeking from mental health services and familial and cultural attitudes towards mental health. There were, however, significant positive associations between knowledge about treatment in the CaKAP and help-seeking, suggesting that either knowledge about the range of treatments available 
might encourage help-seeking or that past experiences of seeking help for mental health problems had improved knowledge of treatments.

Somewhat counterintuitively, greater knowledge about medication in CaKAP was related to increased sensitivity to stigma. Previous research suggests increased knowledge of medication side effects reinforces perceptions of stigma in African-Caribbean communities (Rathod et al., 2010). Consistent with previous research (Vogel et al., 2007), in both samples, higher levels of perceived stigma were related to decreased intentions to seek help from mental health services. Finding ways to decrease public stigma may encourage more people to seek help for psychological problems. These may include public health campaigns to challenge negative societal messages about mental illness and antistigma interventions to provide normalising information and explanations for psychosis (Morrison et al., 2016; Schreiber and Hartrick, 2002). There is modest evidence for the effectiveness of anti-stigma interventions in terms of increasing knowledge and reducing stigmatising attitudes (Mehta et al., 2015). The MED and SYMPTOM subscales of the CaKAP and KAP are the same (include no additional culturally-specific items). The nature of the relationships between these subscales and the measures of stigma and help-seeking were different for the two samples of predominately White British versus African-Caribbean participants. This suggests that the knowledge measures can generate different results across different ethnic or cultural populations.

Both measures were successfully completed online, which suggests they are feasible to deliver electronically and provides support for their acceptability. The content of the knowledge measures was informed by multiple sources, including published literature and expert feedback from professionals, service users, carers and community members thereby potentially increasing their resonance with the experiences of respondents. However, as self-report assessments are subject to response and desirability biases, it is possible that participants' responses reflected these biases versus views they personally endorsed.

The KAP sample was predominately White $(73 \%)$ with relatively high numbers of people working in or studying psychology and both samples comprised a higher percentage of females than males. This means that the sample may not be generalisable to other ethnic groups or less educated people with more limited knowledge of psychology. Recruitment via convenience sampling methods may have contributed to a selection bias towards those people with better knowledge of psychosis or those who were more interested in research. Both samples generally scored highly in terms of knowledge on the KAP and the African-Caribbean sample scored highly on the CaKAP. It is unclear whether the current findings would be replicated in samples with more limited knowledge. One strength of the study is that we were able to examine sociodemographic differences between the KAP and CaKAP samples. However, perhaps due to the nature of the open-ended question in the online survey, missing data for age in both samples was high and therefore related findings should be interpreted with caution. 
Further validation in more socio-demographically diverse samples is required, including service users, carers, family members, healthcare professionals or other non-clinical samples.

It is worth noting that the scoring system may have reduced the sensitivity of the measure in terms of its ability to detect differences in levels of knowledge. The decision was made to score 'don't know' responses higher than 'disagree' as this suggests some ambivalence related to the items and perhaps greater knowledge when compared to strong disagreement with the correct answer. It is recognised that summed scores may mask this level of detail, whereby, for example, an individual with numerous 'don't know' responses could end up with similar scores to an individual with some 'agree' and some 'disagree' responses. An avenue for further research would be to explore different scoring system. However, the current scoring system was deemed acceptable by experts and lay persons in the current study. Further detail of participants' knowledge and belief about psychosis can be obtained through item-level analyses and the open-ended response item at the end of each question. The latter is likely to be more useful in clinical application of the measures.

Another limitation is the low numbers of participants completing the measures again for test-retest reliability, particularly in the CaKAP sample. This meant the CaKAP and the KAP samples had to be combined for the assessments and only the test-retest reliability of the KAP could be examined. Future research should investigate the stability of these measures over time in larger samples, specifically the test re-test reliability of the CaKAP and the sensitivity of both measures to change.

The findings provide limited evidence for construct validity of the CaKAP. Future research should test its relationship with other validated measures such as perceived discrimination, and working alliance or engagement in treatment. Moreover, the reported associations between knowledge on the $\mathrm{KAP}$ and CaKAP, and stigma and help-seeking are cross-sectional and thus causality or directionality cannot be inferred. Validation of both measures in larger samples, where they can be subject to factor analysis to determine the underlying factor structures, is required.

Following further validation, these tools could be used in clinical practice to generate discussion about relatives' and service users' knowledge and beliefs about psychosis. The KAP and CaKAP can also be used to assess current evidence-based knowledge as part of outcome trials for psychosocial interventions for psychosis. Our findings suggest that, for the general population, better outcomes in psychoeducation may be realised through increased knowledge of symptoms, management, and in particular prognosis and available treatments. However, a more targeted approach such as increasing knowledge about how services work and exploring alternatives to medication, such as psychological therapies, may be relevant for African-Caribbean people (Edge et al., 2016; Rathod et al., 2010; Rathod et al., 2013).

This study highlights the need to go beyond direct translation of measures and to assess different conceptualisations of psychological constructs across different cultures. This has wider implications 
for the validity and reliability of standardised measures with other ethnic groups in which their cultural validity has not been formally evaluated. Cross-cultural validation work is required to encourage researchers and clinicians to conduct assessments in more culturally appropriate ways when working with different ethnic populations. The CaKAP can be used as a tool to assess culturally-specific knowledge about psychosis and to guide culturally-appropriate psychosocial interventions. The next step is to test the psychometric properties of the CaKAP in larger clinical samples and in the context of future trials of culturally-appropriate talking therapies for AfricanCaribbean service users and their families.

\section{Acknowledgements}

The authors would like to thank the CaFI Research Advisory Group for their support with the CaFI trial and contributions to this study.

This project was supported by the National Institute for Health Research (NIHR) Health Service and Delivery Research Programme (HS\&DR) (D.E., project number: 12/5001/62).

The views and opinions expressed therein are those of the authors and do not necessarily reflect those of the Health Service and Delivery Research Programme (HS\&DR), NIHR, NHS or the Department of Health

\section{Conflict of interest}

On behalf of all authors, the corresponding author states that there is no conflict of interest. 
Table 1

Sociodemographic characteristics of KAP and CaKAP samples

\begin{tabular}{|c|c|c|c|}
\hline \multirow{2}{*}{ Variable } & \multirow{2}{*}{ Level } & \multirow{2}{*}{$\begin{array}{c}\text { KAP } \\
(n=87)\end{array}$} & \multirow{2}{*}{$\begin{array}{c}\text { CaKAP } \\
(n=79) \\
n(\%)\end{array}$} \\
\hline & & & \\
\hline \multicolumn{4}{|l|}{ Gender } \\
\hline & $\begin{array}{l}\text { Female } \\
\text { Male } \\
\text { Not specified }\end{array}$ & $\begin{array}{c}62(72.1) \\
23(26.7) \\
2(1.2)\end{array}$ & $\begin{array}{c}51(64.6) \\
28(35.4) \\
0\end{array}$ \\
\hline Age & $\begin{array}{l}\text { Mean (SD) } \\
\text { Range }\end{array}$ & $\begin{array}{c}27.82(8.04) \\
19-62\end{array}$ & $\begin{array}{c}42.03(13.36) \\
18-71\end{array}$ \\
\hline \multicolumn{4}{|l|}{ Ethnicity } \\
\hline & $\begin{array}{l}\text { White-British } \\
\text { Other White } \\
\text { Asian } \\
\text { African-Caribbean } \\
\text { Mixed AC } \\
\text { Not specified }\end{array}$ & $\begin{array}{c}64(73.5) \\
12(13.8) \\
9(10.3) \\
1(1.1) \\
0 \\
1(1.1)\end{array}$ & $\begin{array}{c}0 \\
0 \\
0 \\
63(79.7) \\
13(16.5) \\
3(3.8)\end{array}$ \\
\hline \multicolumn{4}{|c|}{ Experience of psychosis } \\
\hline & $\begin{array}{l}\text { Personal } \\
\text { Professional } \\
\text { Educational }\end{array}$ & $\begin{array}{l}17(19.5) \\
29(33.3) \\
53(60.9)\end{array}$ & $\begin{array}{l}51(64.6) \\
24(30.4) \\
21(26.6)\end{array}$ \\
\hline \multicolumn{4}{|c|}{ Profession } \\
\hline & $\begin{array}{l}\text { Employed } \\
\text { Full time students } \\
\text { Unemployed or retired } \\
\text { Not specified }\end{array}$ & $\begin{aligned} 23 & (26.4) \\
62 & (72.3) \\
1 & (1.1) \\
1 & (1.1)\end{aligned}$ & $\begin{array}{c}62(78.5) \\
10(12.7) \\
7(8.9) \\
0\end{array}$ \\
\hline
\end{tabular}

Note: Missing data for age variable: CaKAP sample $n=73 ;$ KAP sample $n=59$.

Table 2.

Descriptive statistics (means, standard deviations and range) for KAP, CaKAP, IASMHS and DDS in the KAP and CaKAP samples 


\begin{tabular}{|c|c|c|c|c|c|}
\hline Sample & Measure & $n$ & Mean & $S D$ & Range \\
\hline \multicolumn{6}{|l|}{ KAP } \\
\hline & KAP total & 86 & 108.01 & 12.37 & $78-130$ \\
\hline & SYMPTOM & 87 & 43.22 & 6.17 & $29-52$ \\
\hline & CAUSE & 87 & 6.54 & 1.63 & $2-8$ \\
\hline & MED & 87 & 24.71 & 4.29 & $14-32$ \\
\hline & TREAT & 86 & 14.16 & 2.30 & $8-16$ \\
\hline & OUTCOME & 86 & 15.35 & 2.38 & $8-18$ \\
\hline & MANAGE & 86 & 3.88 & 0.45 & $1-4$ \\
\hline & IASMHS total & 85 & 66.22 & 12.51 & $29-88$ \\
\hline & Psychological Openness & 85 & 21.54 & 5.50 & $5-31$ \\
\hline & Help-seeking Propensity & 85 & 23.05 & 4.49 & $12-32$ \\
\hline & Indifference to Stigma & 85 & 21.64 & 6.22 & $1-32$ \\
\hline & DDS total & 85 & 43.86 & 9.98 & $20-68$ \\
\hline \multicolumn{6}{|l|}{ CaKAP } \\
\hline & CaKAP total & 68 & 143.57 & 16.49 & $111-177$ \\
\hline & SYMPTOM & 78 & 41.62 & 6.98 & $24-52$ \\
\hline & CAUSE & 75 & 16.97 & 4.24 & $5-22$ \\
\hline & MED & 73 & 24.70 & 4.77 & $12-32$ \\
\hline & TREAT & 68 & 23.35 & 4.52 & $12-30$ \\
\hline & OUTCOME & 68 & 26.66 & 4.11 & $14-32$ \\
\hline & MANAGE & 68 & 9.60 & 0.85 & $6-10$ \\
\hline & KAP total & 68 & 110.75 & 12.44 & $91-135$ \\
\hline & SYMPTOM & 78 & 41.62 & 6.98 & $24-52$ \\
\hline & CAUSE & 75 & 6.64 & 1.49 & $2-8$ \\
\hline & MED & 73 & 24.70 & 4.77 & $12-32$ \\
\hline & TREAT & 68 & 15.09 & 2.95 & $7-18$ \\
\hline & OUTCOME & 68 & 16.22 & 2.61 & $8-20$ \\
\hline & MANAGE & 68 & 5.76 & 0.60 & $3-6$ \\
\hline & IASMHS total & 66 & 67.83 & 12.34 & $21-95$ \\
\hline & Psychological Openness & 66 & 22.94 & 4.75 & $13-32$ \\
\hline & Help-seeking Propensity & 66 & 24.23 & 5.94 & $2-32$ \\
\hline & Indifference to Stigma & 66 & 20.67 & 5.21 & $6-32$ \\
\hline & DDS total & 63 & 45.90 & 8.56 & $24-65$ \\
\hline
\end{tabular}

Note. $\mathrm{KAP}=$ Knowledge about Psychosis; $\mathrm{CaKAP}=$ Culturally-adapted Knowledge about Psychosis;

SYMPTOM=symptoms and problems relating to psychosis; $M E D=$ medication; TREAT $=$ other treatments and services; OUTCOME=course and outcome; MANAGE=management; IASMHS=Inventory of Attitudes Towards Seeking Mental Health Services; DDS=Devaluation Discrimination Scale. N varies across variables due to missing data, handled with listwise deletion. 
Table 3. Pearson's correlations between KAP, DDS and IASMHS

\begin{tabular}{|c|c|c|c|c|c|c|c|c|c|c|c|}
\hline & $\begin{array}{l}\text { DDS } \\
\text { total }\end{array}$ & $\begin{array}{c}\text { IASMHS } \\
\text { total }\end{array}$ & $\begin{array}{c}\text { IASMHS } \\
\text { PO }\end{array}$ & $\begin{array}{c}\text { IASMHS } \\
\text { HSP }\end{array}$ & $\begin{array}{c}\text { IASMHS } \\
\text { ITS }\end{array}$ & $\begin{array}{l}\text { KAP } \\
\text { total }\end{array}$ & SYMP & CAUSE & MED & TREAT & OUT \\
\hline $\begin{array}{l}\text { Psychological } \\
\text { openness }\end{array}$ & $-0.27 *$ & $0.74 * *$ & - & - & - & - & - & - & - & - & - \\
\hline $\begin{array}{l}\text { Help-seeking } \\
\text { propensity }\end{array}$ & $-0.27 *$ & $0.77 * *$ & $0.40^{* *}$ & - & - & - & - & - & - & - & - \\
\hline KAP total & $-0.22 *$ & $0.24 * *$ & 0.21 & $0.30 * *$ & 0.08 & - & - & - & - & - & - \\
\hline SYMPTOM & -0.17 & 0.21 & 0.20 & $0.24 *$ & 0.07 & $0.88^{* *}$ & - & - & - & - & - \\
\hline CAUSE & 0.04 & -0.00 & 0.06 & 0.10 & -0.14 & $0.40 * *$ & $0.29 * *$ & - & - & - & - \\
\hline OUTCOME & -0.12 & $0.34 * *$ & $0.27 *$ & $0.38 * *$ & 0.17 & $0.66^{* *}$ & $0.47 * *$ & $0.29 * *$ & $0.41 * *$ & $0.31 * *$ & - \\
\hline MANAGE & $-0.24 * *$ & 0.10 & -0.07 & 0.07 & 0.21 & 0.19 & 0.10 & -0.01 & 0.17 & 0.12 & 0.12 \\
\hline
\end{tabular}

Note. *Correlation is significant at the 0.05 level. ** Correlation is significant at the 0.01 level. KAP=Knowledge about Psychosis; CaKAP= Culturally-adapted Knowledge about Psychosis; SYMPTOM=symptoms and problems relating to psychosis; MED=medication; TREAT=other treatments and services; OUTCOME=course and outcome; MANAGE=management; IASMHS=Inventory of Attitudes towards Seeking Mental Health Services; DDS=Devaluation Discrimination Scale. 
Table 4. Pearson's correlations between CaKAP, DDS and IASMHS

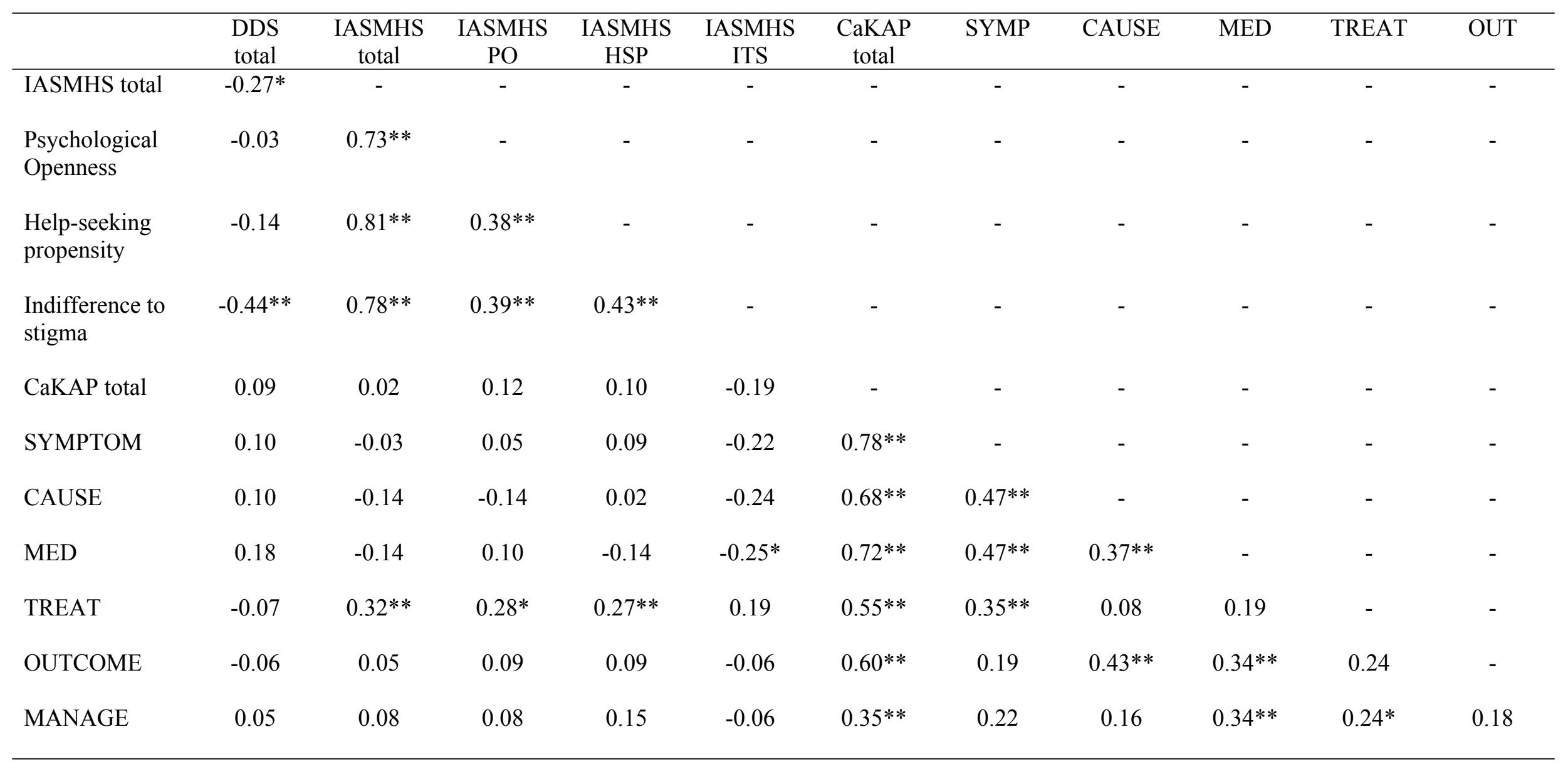

Note. * Correlation is significant at the 0.05 level. ** Correlation is significant at the 0.01 level. KAP=Knowledge about Psychosis; CaKAP $=$ Culturally-adapted Knowledge about Psychosis; SYMPTOM=symptoms and problems relating to psychosis; $\mathrm{MED}=$ medication; TREAT $=$ other treatments and services; OUTCOME=course and outcome; MANAGE=management; IASMHS=Inventory of Attitudes towards Seeking Mental Health Services; DDS=Devaluation Discrimination Scale. 


\section{References}

Awad, A.G., Voruganti, L.N.P., 2008. The burden of schizophrenia on caregivers - A review. Pharmacoeconomics 26, 149-162.

Barrowclough, C., Tarrier, N., 1992. Families of schizophrenic patients: Cognitive behavioural intervention. Chapman \& Hall, London.

Barrowclough, C., Tarrier, N., Watts, S., Vaughn, C., Bamrah, J.S., Freeman, H.L., 1987. Assessing the functional value of relatives' knowledge about schizophrenia: a preliminary report. The British journal of psychiatry : the journal of mental science 151, 1-8.

Bathje, G., Pryor, J., 2011. The relationships of public and self-stigma to seeking mental health services. Journal of Mental Health Counseling 33, 161-176.

Bhui, K., Stansfeld, S., Hull, S., Priebe, S., Mole, F., Feder, G., 2003. Ethnic variations in pathways to and use of specialist mental health services in the UK. Systematic review. Brit J Psychiat 182, 105-116.

Brown, G., Marshall, M., Bower, P., Woodham, A., Waheed, W., 2014. Barriers to recruiting ethnic minorities to mental health research: a systematic review. Int J Method Psych 23, 3648.

Cantor-Graae, E., Selten, J.P., 2005. Schizophrenia and migration: a meta-analysis and review. American Journal of Psychiatry 162, 12-24.

DeVon, H.A., Block, M.E., Moyle-Wright, P., Ernst, D.M., Hayden, S.J., Lazzara, D.J., Savoy, S.M., Kostas-Polston, E., 2007. A psychometric toolbox for testing validity and reliability. J Nurs Scholarship 39, 155-164.

Dixon, L., Dickerson, F., Bellack, A.S., Bennett, M., Dickinson, D., Goldberg, R.W., Lehman, A., Tenhula, W.N., Calmes, C., Pasillas, R.M., 2010. The 2009 schizophrenia PORT psychosocial treatment recommendations and summary statements. Schizophrenia bulletin $36,48-70$.

Edge, D., Degnan, A., Cotterill, S., Berry, K., Drake, R., Baker, J., Barrowclough, C., Hughes-Morley, A., Grey, P., Bhugra, D., 2016. Culturally-adapted Family Intervention (CaFI) for African-Caribbeans diagnosed with schizophrenia and their families: a feasibility study protocol of implementation and acceptability. Pilot and Feasibility Studies 2, 2-39.

Fearon, P., Kirkbride, J., Morgan, C., Dazzan, P., Morgan, K., Lloyd, T., Hutchinson, G., Tarrant, J., Fung, W., Holloway, J., Mallett, R., Harrison, G., Leff, J., Jones, P., Murray, R., 2006. Incidence of schizophrenia and other psychoses in ethnic minority groups: results from the MRC AESOP Study. Psychological Medicine 36, 1541-1550.

Field, A., 2013. Discovering statistics using IBM SPSS statistics. Sage.

Geekie, J., Read, J., 2009. Making sense of madness: Contesting the meaning of schizophrenia. Routledge.

Haynes, S.N., Richard, D., Kubany, E.S., 1995. Content validity in psychological assessment: A functional approach to concepts and methods. Psychol Assessment 7, 238.

HM Government, 2007. The Mental Health Act, Section 12. 
Keating, F., Robertson, D., McCulloch, A., Francis, E., 2002. Breaking the circles of fear: A review of the relationship between mental health services and African and Caribbean communities. Sainsbury Centre for Mental Health London.

Kirkbride, J.B., Fearon, P., Morgan, C., Dazzan, P., Morgan, K., Tarrant, J., Lloyd, T., Holloway, J., Hutchinson, G., Leff, J.P., Mallett, R.M., Harrison, G.L., Murray, R.M., Jones, P.B., 2006. Heterogeneity in incidence rates of schizophrenia and other psychotic syndromes - Findings from the 3-center AESOP study. Arch Gen Psychiat 63, 250-258.

Kovandžić, M., Chew-Graham, C., Reeve, J., Edwards, S., Peters, S., Edge, D., Aseem, S., Gask, L., Dowrick, C., 2011. Access to primary mental health care for hard-to-reach groups: from 'silent suffering'to 'making it work'. Social science \& medicine 72, 763-772.

Link, B.G., Mirotznik, J., Cullen, F.T., 1991. The effectiveness of stigma coping orientations: Can negative consequences of mental illness labeling be avoided? Journal of Health and Social Behavior, 302-320.

Lobban, F., Barrowclough, C., Jones, S., 2005. Assessing cognitive representations of mental health problems. I. The illness perception questionnaire for schizophrenia. The British journal of clinical psychology / the British Psychological Society 44, 147-162.

Lynn, M.R., 1986. Determination and quantification of content validity. Nurs Res 35, 382386.

Mackenzie, C.S., Knox, V.J., Gekoski, W.L., Macaulay, H.L., 2004. An adaptation and extension of the attitudes toward seeking professional psychological help scale. J Appl Soc Psychol 34, 2410-2435.

Mallett, R., Leff, J., Bhugra, D., Pang, D., Zhao, J.H., 2002. Social environment, ethnicity and schizophrenia A case-control study. Social psychiatry and psychiatric epidemiology 37, 329-335.

Mantovani, N., Pizzolati, M., Edge, D., 2017. Exploring the relationship between stigma and help-seeking for mental illness in African-descended faith communities in the UK. Health expectations : an international journal of public participation in health care and health policy 20, 373-384.

Mas, A., Hatim, A., 2002. Stigma in mental illness: attitudes of medical students towards mental illness. The Medical Journal of Malaysia 57, 433-444.

McFarlane, W.R., Dixon, L., Lukens, E., Lucksted, A., 2003. Family psychoeducation and schizophrenia: a review of the literature. Journal of Marital and Family Therapy 29, 223-245.

Mehta, N., Clement, S., Marcus, E., Stona, A.C., Bezborodovs, N., Evans-Lacko, S., Palacios, J., Docherty, M., Barley, E., Rose, D., Koschorke, M., Shidhaye, R., Henderson, C., Thornicroft, G., 2015. Evidence for effective interventions to reduce mental health-related stigma and discrimination in the medium and long term: systematic review. The British journal of psychiatry : the journal of mental science 207, 377-384.

Morgan, C., Kirkbride, J., Leff, J., Craig, T., Hutchinson, G., McKenzie, K., Morgan, K., Dazzan, P., Doody, G.A., Jones, P., 2007. Parental separation, loss and psychosis in different ethnic groups: a case-control study. Psychological Medicine 37, 495-504.

Morgan, C., Mallett, R., Hutchinson, G., Bagalkote, H., Morgan, K., Fearon, P., Dazzan, P., Boydell, J., McKenzie, K., Harrison, G., Murray, R., Jones, P., Craig, T., Leff, J., Group., A.S., 2005. Pathways to care and ethnicity. 2: Source of referral and help-seeking - Report from the AESOP study. Brit J Psychiat 186, 290-296. 
Morgan, C., Mallett, R., Hutchinson, G., Leff, J., 2004. Negative pathways to psychiatric care and ethnicity: the bridge between social science and psychiatry. Social science \& medicine $58,739-752$.

Morrison, A.P., Burke, E., Murphy, E., Pyle, M., Bowe, S., Varese, F., Dunn, G., Chapman, N., Hutton, P., Welford, M., 2016. Cognitive therapy for internalised stigma in people experiencing psychosis: A pilot randomised controlled trial. Psychiatry research 240, 96-102.

National Institute for Health and Care Excellence, 2009. Schizophrenia: The NICE Guideline on Core Interventions in the Treatment and Management of Schizophrenia in Adults in Primary and Secondary Care. The British Psychological Society and the Royal College of Psychiatrists, London.

National Institute for Health and Care Excellence, 2014. Psychosis and schizophrenia in adults: treatment and management. NICE clinical guidelines. Department of Health, London.

Pharoah, F., Mari, J., Rathbone, J., Wong, W., 2010. Family intervention for schizophrenia. Cochrane Db Syst Rev.

Pyle, M., Morrison, A.P., 2013. "It's just a very taboo and secretive kind of thing": making sense of living with stigma and discrimination from accounts of people with psychosis. Psychosis 6, 195-205.

Rathod, S., Kingdon, D., Phiri, P., Gobbi, M., 2010. Developing culturally sensitive cognitive behaviour therapy for psychosis for ethnic minority patients by exploration and incorporation of service users' and health professionals' views and opinions. Behav Cogn Psychoth 38, 511 533.

Rathod, S., Phiri, P., Harris, S., Underwood, C., Thagadur, M., Padmanabi, U., Kingdon, D., 2013. Cognitive behaviour therapy for psychosis can be adapted for minority ethnic groups: A randomised controlled trial. Schizophr Res 143, 319-326.

Rüsch, N., Evans-Lacko, S.E., Henderson, C., Flach, C., Thornicroft, G., 2011. Knowledge and attitudes as predictors of intentions to seek help for and disclose a mental illness.

Psychiat Serv 62, 675-678.

Schreiber, R., Hartrick, G., 2002. Keeping it together: how women use the biomedical explanatory model to manage the stigma of depression. Issues in mental health nursing 23 , 91-105.

Shefer, G., Rose, D., Nellums, L., Thornicroft, G., Henderson, C., Evans-Lacko, S., 2013. 'Our community is the worst': the influence of cultural beliefs on stigma, relationships with family and help-seeking in three ethnic communities in London. The International journal of social psychiatry 59, 535-544.

Singh, S.P., Greenwood, N., White, S., Churchill, R., 2007. Ethnicity and the Mental Health Act 1983. The British journal of psychiatry : the journal of mental science 191, 99-105.

Smith, G., Higgs, A., Gregory, K., 2007. An Integrated Approach to Family Work for Psychosis: A Manual for Family Workers. Jessica KIngsley Publishers, London.

The British Psychological Society, D.o.C.P., 2014. Understanding psychosis and schizophrenia: why people sometimes hear voices, believe things that others find strange, or appear out of touch with reality, and what can help, in: Cooke, A., Kinderman, P. (Eds.).

The Schizophrenia Commission, 2012. The abondoned illness: a report from the Schizophrenia Commission Rethink Mental Illness, London. 
Vogel, D.L., Wade, N.G., Hackler, A.H., 2007. Perceived public stigma and the willingness to seek counseling: The mediating roles of self-stigma and attitudes toward counseling. $J$ Couns Psychol 54, 40-50.

Waheed, W., Woodham, A., Hughes-Morley, A., Allen, G., Bower, P., 2015. Overcoming barriers to recruiting ethnic minorities to mental health research: a typology of recruitment strategies. BioMedCentral Psychiatry 15, 101.

Wood, L., Burke, E., Byrne, R., Pyle, M., Chapman, N., Morrison, A., 2014. Stigma in psychosis: A thematic synthesis of current qualitative evidence. Psychosis 7, 152-165. 


\section{KNOWLEDGE ABOUT PSYCHOSIS QUESTIONNAIRE}

This questionnaire aims to assess your knowledge about psychosis. Psychosis is a mental health problem. Some people who experience psychosis may be diagnosed with schizophrenia. For each item please select Agree, Disagree or Don't Know. All responses given in the questionnaire will remain confidential.

\section{SYMPTOMS AND PROBLEMS RELATING TO PSYCHOSIS}

\subsection{Which of the following are symptoms associated with psychosis?}

1.1.1. Hearing things that others are not hearing

1.1.2. Difficulties with thinking and concentrating

1.1.3. Seeing things that others are not seeing

1.1.4. Unusual beliefs that others do not share

1.1.5. Paranoia

1.1.6. Lack of drive or energy to do things

1.1.7. Smelling things that others are not smelling

1.1.8. Not expecting to be able to enjoy things

1.1.9. Grandiose religious thoughts (grandiose means an over-inflated sense of worth, power, knowledge, or identity)

1.1.10. Talking in a way that other people find hard to follow

$\begin{array}{ll}\text { Agree } & \text { Disagree } \\ \text { Agree } & \text { Disagree } \\ \text { Agree } & \text { Disagree } \\ \text { Agree } & \text { Disagree } \\ \text { Agree } & \text { Disagree } \\ \text { Agree } & \text { Disagree }\end{array}$

Agree Disagree

Agree Disagree

Agree Disagree

Agree Disagree
Don't Know

Don't Know

Don't Know

Don't Know

Don't Know

Don't Know

Don't Know

Don't Know

Don't Know

Don't Know

Are there any other symptoms you can think of?

1.2. Which of the following could be problems relating to psychosis?

1.2.1. Feeling depressed

1.2.2. Low self esteem

1.2.3. Problems or difficulties sleeping

1.2.4. Feeling very anxious

1.2.5. Misusing drugs

1.2.6. Physical health problems

1.2.7. Difficulty in keeping up with work or school

1.2.8. Difficulty managing money

1.2.9. Feeling threatened

1.2.10. Not looking after self

1.2.11. Lack of goals or hope for the future

1.2.12. Self-harm or suicidal thoughts

1.2.13. Wanting to be alone

\section{Agree}

Agree

Agree

Agree

Agree

Agree

Agree

Agree

Agree

Agree

Agree

Agree

Agree
Disagree

Disagree

Disagree

Disagree

Disagree

Disagree

Disagree

Disagree

Disagree

Disagree

Disagree

Disagree

Disagree
Don't Know

Don't Know

Don't Know

Don't Know

Don't Know

Don't Know

Don't Know

Don't Know

Don't Know

Don't Know

Don't Know

Don't Know

Don't Know

Are there any other problems you can think of? 


\subsection{Which of the following statements about psychosis are correct?}

1.3.1. Psychotic experiences are experienced by up to $10 \%$ of the general population at some point in their life

1.3.2. Some people find psychotic experiences positive

1.3.3. The longer the length of time between becoming unwell and receiving help for psychosis the worse the recovery outcome

Agree

Disagree

Don't Know

Agree Disagree Don't Know

Agree Disagree Don't Know

2. CAUSE

2.1. Which of the following may increase someone's risk of being diagnosed with psychosis?

2.1.1. Having close relatives with psychosis

2.1.2. Hardship, for example, poor housing and having no money

2.1.3. Abuse or neglect in childhood

2.1.4. Misusing drugs
Agree

Agree

Agree

Agree
Disagree

Disagree

Disagree

Disagree
Don't Know

Don't Know

Don't Know

Don't Know

Are there any other risk factors you can think of?

\section{MEDICATION}

3.1. Which of the follow do you think are possible reasons for medication being prescribed for a person with psychosis?

3.1.1. To help with sleeping

3.1.2. To reduce the symptoms, such as the distress associated with voices or unusual beliefs

3.1.3. To help them think clearer

3.1.4. To calm them

3.1.5. To improve everyday functioning
Agree

Agree

Agree

Agree

Agree
Disagree

Disagree

Disagree

Disagree

Disagree
Don't Know

Don't Know

Don't Know

Don't Know

Don't Know

Are there any other reasons you can think of? 
3.2. Which of the following might be side-effects of medication for psychosis?
3.2.1. Weight gain
3.2.2. Restlessness
3.2.3. Loss of menstruation
3.2.4. Lack of sex drive
3.2.5. Increased risk of diabetes
3.2.6. Slowing of thought
3.2.7. Loss of fertility
3.2.8. Dizziness or confusion
3.2.9. Feeling agitated
3.2.10. Facial movements or spasms
3.2.11. Loss of energy

$\begin{array}{lll}\text { Agree } & \text { Disagree } & \text { Don't Know } \\ \text { Agree } & \text { Disagree } & \text { Don't Know } \\ \text { Agree } & \text { Disagree } & \text { Don't Know } \\ \text { Agree } & \text { Disagree } & \text { Don't Know } \\ \text { Agree } & \text { Disagree } & \text { Don't Know } \\ \text { Agree } & \text { Disagree } & \text { Don't Know } \\ \text { Agree } & \text { Disagree } & \text { Don't Know } \\ \text { Agree } & \text { Disagree } & \text { Don't Know } \\ \text { Agree } & \text { Disagree } & \text { Don't Know } \\ \text { Agree } & \text { Disagree } & \text { Don't Know } \\ \text { Agree } & \text { Disagree } & \text { Don't Know }\end{array}$

Are there any other side-effects you can think of?

\section{OTHER TREATMENTS AND SERVICES}

4.1. Which of the following treatments are recommended by Government (NICE) guidelines for people experiencing psychosis?
4.1.1. Family therapy
Agree
Disagree
Don't Know
4.1.2. Cognitive Behavioural Therapy (CBT), a type of talking therapy
Agree Disagree Don't Know
4.1.3. Arts therapies e.g. art, drama, dance, music)
Agree
Disagree
Don't Know

Are there any other treatments you can think of?

4.2. Which of the following professionals can provide some form of support for people experiencing psychosis?
4.2.1. General Practitioner (GP)
4.2.2. Social worker
4.2.3. Occupational therapist
4.2.4. Psychiatrist
4.2.5. Support Worker
4.2.6. Psychologist

Agree

Disagree

Don't Know

Agree

Disagree

Don't Know

Agree

Disagree

Don't Know

Agree

Disagree

Don't Know

Agree

Disagree

Don't Know

Agree

Disagree

Don't Know

Are there any other professionals you can think of? 


\section{KNOWLEDGE ABOUT PSYCHOSIS QUESTIONNAIRE}

\section{COURSE AND OUTCOME}

5.1. Which of the following are likely to make psychosis worse or bring the problems back?

5.1.1. Not having meaningful things to do Agree Disagree Don't Know

5.1.2. Stressful life events Agree Disagree Don't Know

5.1.3. Suddenly stopping medication Agree Disagree Don't Know

5.1.4. Misusing drugs Agree Disagree Don't Know

5.1.5. Not having regular contact with people Agree Disagree Don't Know

5.1.6. Being criticised by other people Agree Disagree Don't Know

Are there any other problems you can think of?

5.2. Which of the following are the possible outcomes following one episode of psychosis?

5.2.1. Never having another

5.2.2. Get better, then get worse, but be okay in between

5.2.3. Always have symptoms and need some long-term help

5.2.4. Have long term experiences of psychosis but do not require support
Agree Disagree Don't Know

Agree Disagree Don't Know

Agree Disagree Don't Know

Agree Disagree Don't Know

Are there any other outcomes you can think of?

\section{MANAGEMENT}

6.1. Would any of the following actions by family or friends improve the condition of a person experiencing psychosis and help them to stay well?
6.1.1. Supporting them in taking medication
Agree Disagree
Don't Know
6.1.2. Encouraging them to gradually get back to doing things for themselves
Agree Disagree Don't Know

6.1.3. Encouraging contact with the wider community, for example, in community groups

Agree Disagree Don't Know

Are there any other actions you can think of? 
KNOWLEDGE ABOUT PSYCHOSIS QUESTIONNAIRE 


\section{CULTURALLY-ADAPTED KNOWLEDGE ABOUT PSYCHOSIS QUESTIONNAIRE}

This questionnaire aims to assess your knowledge about psychosis. Psychosis is a mental health problem. Some people who experience psychosis may be diagnosed with schizophrenia. For each item please select Agree, Disagree or Don’t Know. All responses will remain confidential.

\section{SYMPTOMS AND PROBLEMS RELATING TO PSYCHOSIS}

1.1. Which of the following are symptoms associated with psychosis?

1.1.1. Hearing things that others are not hearing

1.1.2. Difficulties with thinking and concentrating Agree

Disagree

Don't Know

1.1.3. Seeing things that others are not seeing

Agree

Disagree

Don't Know

1.1.4. Unusual beliefs that others do not share

Agree

Disagree

Don't Know

1.1.5. Paranoia

Agree

Disagree

Don't Know

1.1.6. Lack of drive or energy to do things

Agree

Disagree

Don't Know

1.1.7. Smelling things that others are not smelling

Agree

Disagree

Agree Disagree

Don't Know

1.1.8. Not expecting to be able to enjoy things

1.1.9. Grandiose religious thoughts (grandiose means an over-inflated sense of worth, power, knowledge, or identity)

Agree Disagree

Don't Know

Don't Know

Agree Disagree Don't Know

1.1.10. Talking in a way that other people find hard to follow

Agree Disagree

Don't Know

Are there any other symptoms you can think of?

1.2. Which of the following could be problems relating to psychosis?

1.2.1. Feeling depressed, down or flat

1.2.2. Low self-esteem

1.2.3. Problems or difficulties sleeping

1.2.4. Feeling very anxious

1.2.5. Misusing drugs

1.2.6. Physical health problems

1.2.7. Difficulty in keeping up with work or school

1.2.8. Difficulty managing money

1.2.9. Feeling threatened

1.2.10. Not looking after self

1.2.11. Lack of goals or hope for the future

1.2.12. Self-harm or suicidal thoughts

1.2.13. Wanting to be alone
Agree Disagree

Agree Disagree

Agree Disagree

Agree Disagree

Agree Disagree

Agree

Agree

Agree

Agree

Agree

Agree

Agree

Agree
Don't Know

Don't Know

Don't Know

Don't Know

Don't Know

Don't Know

Don't Know

Don't Know

Don't Know

Don't Know

Don't Know

Don't Know

Don't Know

Are there any other problems you can think of? 
1.3. Which of the following statements about psychosis are correct?

1.3.1. Psychotic experiences are experienced by up to $10 \%$ of the general population at some point in their life

1.3.2. Some people find psychotic experiences positive

1.3.3. The longer the length of time between becoming unwell and receiving help for psychosis the worse the recovery outcome
Agree Disagree Don't Know

Agree Disagree Don't Know

Agree Disagree Don't Know 


\section{CAUSE}

2.1. Which of the following may increase someone's risk of being diagnosed with psychosis?

2.1.1. Having close relatives with psychosis

2.1.2. Hardship, for example, poor housing and having no money

2.1.3. Abuse or neglect in childhood

2.1.4. Spiritual causes such as Obeah/ demons

2.1.5. $\quad$ Misusing drugs
Agree

Disagree

Agree

Disagree

Agree

Agree

Agree
Disagree

Disagree

Disagree
Don't Know

Don't Know

Don't Know

Don't Know

Don't Know

Are there any other risk factors you can think of?

2.2. Which of the following have been suggested as risk factors for African Caribbean people being diagnosed with psychosis?

2.2.1. Antisocial behaviour e.g. crime or getting in with the wrong crowd

Agree Disagree Don't Know

2.2.2. Racist attacks or events

2.2.3. Feeling excluded and discriminated against in everyday life

Agree Disagree Don't Know

Agree Disagree Don't Know

2.2.4. Institutional racism such as in education or social and health care services

Agree Disagree Don't Know

2.2.5. Not reaching high expectations in school or employment

Agree Disagree Don't Know

2.2.6. Reduced sense of belonging

Agree Disagree

Don't Know

Are there any other risk factors for African Caribbean people you can think of? 
3. MEDICATION

3.1. Which of the follow do you think are possible reasons for medication being prescribed for a person with psychosis?

3.1.1. To help with sleeping

3.1.2. To reduce the symptoms, such as the distress associated with voices or unusual beliefs

3.1.3. To help them think clearer

3.1.4. To calm them

3.1.5. To improve everyday functioning
Agree Disagree Don't Know

Agree Disagree Don't Know

Agree Disagree Don't Know

Agree Disagree Don't Know

Agree Disagree Don't Know

Are there any other reasons you can think of?

3.2. Which of the following might be side-effects of medication for psychosis?

$\begin{array}{lllll}\text { 3.2.1. } & \text { Weight gain } & \text { Agree } & \text { Disagree } & \text { Don't Know } \\ \text { 3.2.2. } & \text { Restlessness } & \text { Agree } & \text { Disagree } & \text { Don't Know } \\ \text { 3.2.3. } & \text { Loss of menstruation } & \text { Agree } & \text { Disagree } & \text { Don't Know } \\ 3.2 .4 . & \text { Lack of sex drive } & \text { Agree } & \text { Disagree } & \text { Don't Know } \\ 3.2 .5 . & \text { Increased risk of diabetes } & \text { Agree } & \text { Disagree } & \text { Don't Know } \\ 3.2 .6 . & \text { Slowing of thought } & \text { Agree } & \text { Disagree } & \text { Don't Know } \\ 3.2 .7 . & \text { Loss of fertility } & \text { Agree } & \text { Disagree } & \text { Don't Know } \\ 3.2 .8 . & \text { Dizziness or confusion } & \text { Agree } & \text { Disagree } & \text { Don't Know } \\ 3.2 .9 . & \text { Feeling agitated } & \text { Agree } & \text { Disagree } & \text { Don't Know } \\ 3.2 .10 . & \text { Facial movements or spasms } & \text { Agree } & \text { Disagree } & \text { Don't Know } \\ 3.2 .11 . & \text { Loss of energy } & \text { Agree } & \text { Disagree } & \text { Don't Know }\end{array}$

Are there any other side-effects you can think of? 


\section{OTHER TREATMENTS AND SERVICES}

4.1. Which of the following treatments are recommended by Government (NICE) guidelines for people experiencing psychosis?
4.1.1. Family therapy
Agree
Disagree
Don't Know
4.1.2. Cognitive Behavioural Therapy (CBT), a type of talking therapy
Agree
Disagree
Don't Know
4.1.3. Arts therapies (e.g. art, drama, dance, music)
Agree
Disagree
Don't Know

Are there any other treatments you can think of?

4.2. Which of the following can provide some form of support for people experiencing psychosis?
4.2.1. General Practitioner (GP)
Agree
Disagree
Don't Know
4.2.2. Social worker
Agree
Disagree
Don't Know
4.2.3. Occupational therapist
Agree
Disagree
Don't Know
4.2.4. Psychiatrist
Agree
Disagree
Don't Know
4.2.5. Pastor or spiritual leader
Agree
Disagree
Don't Know
4.2.6. Support Worker
Agree
Disagree
Don't Know
4.2.7. Psychologist
Agree
Disagree
Don't Know

Are there any others you can think of?

4.3. Which of the following should you contact when a person with psychosis are in crisis?

4.3.1. Mental health crisis team

4.3.2. Accident and Emergency or casualty

4.3.3. General Practitioner (GP)

4.3.4. Police

4.3.5. Care coordinator (person who manages care plan)
Agree

Agree

Agree

Agree

Agree
Disagree

Disagree

Disagree

Disagree

Disagree
Don't Know

Don't Know

Don't Know

Don't Know

Don't Know

Are there any other professionals you can think of? 


\section{COURSE AND OUTCOME}

5.1. Which of the following are likely to make psychosis worse or bring the problems back?

5.1.1. Not having meaningful things to do

5.1.2. Stressful life events

5.1.3. Poor physical health care

5.1.4. Suddenly stopping medication

5.1.5. Others staying away due to fear or stigma

5.1.6. Not being able to trust people in charge of care

5.1.7. Misusing drugs

5.1.8. Not having regular contact with people

5.1.9. Being told to 'pull yourself together'

5.1.10. Being criticised by other people

5.1.11. Losing touch with family and friends after long term stay in hospital

5.1.12. Self-medication
Agree Disagree

Agree Disagree

Agree Disagree

Agree Disagree

Agree Disagree

Agree Disagree

Agree Disagree

Agree Disagree

Agree Disagree

Agree Disagree

Agree Disagree

Agree Disagree
Don't Know

Don't Know

Don't Know

Don't Know

Don't Know

Don't Know

Don't Know

Don't Know

Don't Know

Don't Know

Don't Know

Don't Know

Are there any other problems you can think of?

5.2. Which of the following are the possible outcomes following one episode of psychosis?

5.2.1. Never having another

5.2.2. Get better, then get worse, but be okay in between

5.2.3. Always have symptoms and need some long-term help

5.2.4. Have long term experiences of psychosis but do not require support

$\begin{array}{lll}\text { Agree } & \text { Disagree } & \text { Don't Know } \\ \text { Agree } & \text { Disagree } & \text { Don't Know } \\ \text { Agree } & \text { Disagree } & \text { Don't Know } \\ & & \\ \text { Agree } & \text { Disagree } & \text { Don't Know }\end{array}$

Are there any other outcomes you can think of? 


\section{MANAGEMENT}

6.1. Would any of the following actions by family or friends improve the condition of a person experiencing psychosis and help them to stay well?

6.1.1. Supporting them in taking medication

6.1.2. Being hopeful about recovery

6.1.3. Encouraging them to gradually get back to doing things for themselves

6.1.4. Encouraging contact with the wider community, for example, in church or community groups

6.1.5. Family or friends doing things to manage their own stress such as listening to music, prayer, relaxation, meditation

$\begin{array}{lll}\text { Agree } & \text { Disagree } & \text { Don't Know } \\ \text { Agree } & \text { Disagree } & \text { Don't Know } \\ \text { Agree } & \text { Disagree } & \text { Don't Know } \\ & & \\ \text { Agree } & \text { Disagree } & \text { Don't Know }\end{array}$

Agree Disagree Don't Know

Are there any other actions you can think of? 